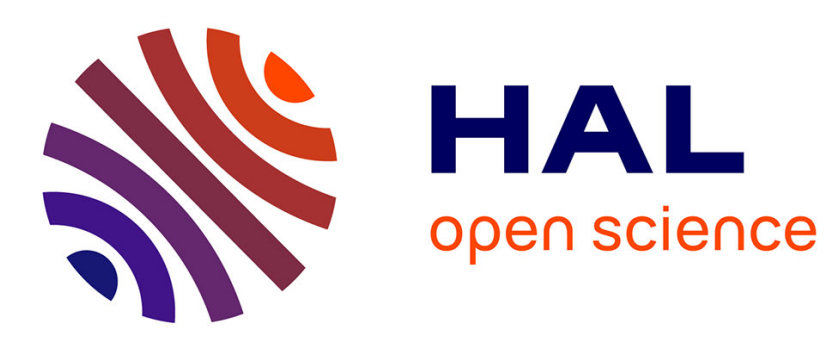

\title{
Posture and Cognition Interfere in Later Adulthood even without Concurrent Response Production
}

\author{
Caroline Smolders, Mihalis Doumas, Ralf Th. Krampe
}

\section{To cite this version:}

Caroline Smolders, Mihalis Doumas, Ralf Th. Krampe. Posture and Cognition Interfere in Later Adulthood even without Concurrent Response Production. Human Movement Science, 2010, 29 (5), pp.809. 10.1016/j.humov.2009.07.009 . hal-00677315

\section{HAL Id: hal-00677315 https://hal.science/hal-00677315}

Submitted on 8 Mar 2012

HAL is a multi-disciplinary open access archive for the deposit and dissemination of scientific research documents, whether they are published or not. The documents may come from teaching and research institutions in France or abroad, or from public or private research centers.
L'archive ouverte pluridisciplinaire HAL, est destinée au dépôt et à la diffusion de documents scientifiques de niveau recherche, publiés ou non, émanant des établissements d'enseignement et de recherche français ou étrangers, des laboratoires publics ou privés. 


\section{Accepted Manuscript}

Posture and Cognition Interfere in Later Adulthood even without Concurrent Response Production

Caroline Smolders, Mihalis Doumas, Ralf Th. Krampe

PII:

S0167-9457(09)00074-8

DOI:

10.1016/j.humov.2009.07.009

Reference:

HUMOV 1167

To appear in:

Human Movement Science

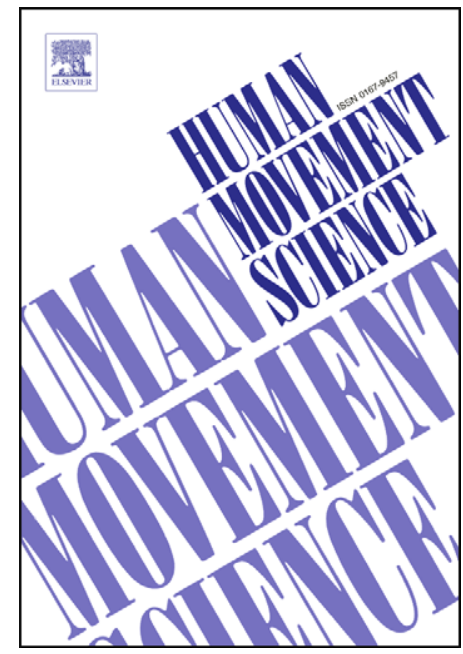

Please cite this article as: Smolders, C., Doumas, M., Krampe, R.T., Posture and Cognition Interfere in Later Adulthood even without Concurrent Response Production, Human Movement Science (2009), doi: 10.1016/ j.humov.2009.07.009

This is a PDF file of an unedited manuscript that has been accepted for publication. As a service to our customers we are providing this early version of the manuscript. The manuscript will undergo copyediting, typesetting, and review of the resulting proof before it is published in its final form. Please note that during the production process errors may be discovered which could affect the content, and all legal disclaimers that apply to the journal pertain. 
Posture and Cognition Interfere in Later Adulthood even without Concurrent Response Production

Caroline Smolders, Mihalis Doumas, \& Ralf Th. Krampe

Katholieke Universiteit Leuven

Corresponding author:

Caroline Smolders

Department of Psychology

Katholieke Universiteit Leuven

Tiensestraat 102 Box 3715

B-3000 Leuven

Belgium

E-mail: caroline.smolders@psy.kuleuven.be

Phone: +3216326146

Fax: +3216326144

Acknowledgements:

The authors acknowledge financial support through BOF grant OT25/05 from the Research Council of KU Leuven and FWO grant G.0379.06 awarded to RK. MD is a postdoctoral fellow of the Fund for Scientific Research - Flanders. We thank Jessie Van den Eynde for help with data collection. 
Interference of posture and cognition

Posture and cognition interfere in later adulthood even without concurrent response production

\section{Introduction}

Sensorimotor tasks such as upright stance used to be considered as automatic, requiring minimal cognitive involvement. Dual-task studies assessing concurrent sensorimotor-cognitive performance have challenged this assumption by showing decrements in dual- compared to single-task performance, so-called dual-task costs. A number of age comparative dual-task studies have shown pronounced dual-task costs in older compared with young adults [for an overview see Li, Krampe, \& Bondar (2005); for exceptions see Kemper, Herman, \& Lian (2003)], and several authors have argued that this reflects increased demands for cognitive resources on the part of sensorimotor processes in the elderly (Lindenberger, Marsiske, \& Baltes, 2000; Woollacott \& Shumway-Cook, 2002).

This interpretation, however, has not remained unchallenged. Two issues feature most prominently in the critique raised. First, dual-task studies frequently used identical levels of cognitive task difficulty for all participants, arguably disadvantaging older adults from the start. If relatively more available resources are occupied by a cognitive task that is more difficult for older adults, they can invest fewer resources into the sensorimotor task to begin with. Similarly, a cognitive task not fully occupying young adults' resources, might lead to the erroneous interpretation of "automatic" sensorimotor performance in that group. The second critique concerns concurrent production of motor responses for both tasks, like pressing buttons with the hands. According to Hartley (2001), output interference at the level of the "response-bottleneck" is typical in dual-task studies and he argues that the described negative age effects largely reflect differences in peripheral processing stages. Indeed, in his studies, age differences in dual-task performance disappeared when concurrent response production was eliminated or reduced (Hartley, 2001; Hartley \& Little, 1999). 
The aims of this paper are twofold. First we review adult age comparative studies assessing concurrent sensorimotor and cognitive performance to evaluate whether the evidence for increased cognitive resource demands of sensorimotor performance in later adulthood is indeed susceptible to the described critique. Second, we present a study that compared dual-task costs for concurrent working memory and postural control performances in young and older adults while avoiding the critical shortcomings of earlier studies.

1.1 Evidence for pronounced dual-task costs in older adults

Dual-task studies assessing concurrent sensorimotor and cognitive performance have been using sensorimotor tasks such as upright stance (Doumas, Rapp, \& Krampe, 2009; Doumas, Smolders, \& Krampe, 2008), walking (Lovden, Schaefer, Pohlmeyer, \& Lindenberger, 2008), force control (Voelcker-Rehage \& Alberts, 2007), tapping (Krampe, Doumas, Lavrysen, \& Rapp, under review), and coordination of hand-foot movements (Heuninckx, Debaere, Wenderoth, Verschueren, \& Swinnen, 2004). In Tables 1A and B, we present an overview of adult age comparative studies assessing concurrent sensorimotor and cognitive performance. Our listing makes no claims for completeness. We rather focussed on studies in which both sensorimotor and cognitive performances were thoroughly analyzed in their own rights, leaving out, for example a vast literature employing the traditional secondary task paradigm [for a more extensive review, see Li et al. (2005)].

Decrements in dual- compared to single-task performance, or dual-task costs (DTCs), suggest that sensorimotor processes require cognitive involvement. As can be seen in Tables $1 \mathrm{~A}$ and $\mathrm{B}$, patterns of resource allocation in dual-task situations differ across studies, with some showing DTCs in the sensorimotor domain (Maylor, Allison, \& Wing, 2001; ShumwayCook, Woollacott, Kerns, \& Baldwin, 1997) others showing DTCs in both domains (Lindenberger et al., 2000; Shumway-Cook \& Woollacott, 2000), and still others showing 
trade-offs so that performance in one domain is improved at the expense of performance in the other domain (Doumas et al., 2008; Rapp, Krampe, \& Baltes, 2006). In general, DTCs are pronounced in older adults. The prevalent theoretical explanation for these age differences is that of diminished resources in later adulthood [for a review of theories explaining dual-task performance, see Lacour, Bernard-Demanze, \& Dumitrescu (2008)]. However, several authors (e.g., Hartley \& Little, 1999; Somberg \& Salthouse, 1982) have argued that attributing age differences in dual-task decrements to a reduction in central resources is premature and have pointed at methodological shortcomings in dual-task studies.

-Insert Tables 1A and B about here-

\subsection{Age differential single-task performance and concurrent response production}

Few dual-task studies have equated cognitive challenge and single-task performance levels across age groups and those who did produced a mixture of results. Somberg and Salthouse (1982) observed no age differences in divided attention abilities after equating single-task performance levels. In contrast, Doumas et al. (2008) equated single-task cognitive performance levels by individually calibrating task difficulty, and still found agerelated decline in dual-task performance.

A second issue to consider relates to concurrent response production i.e., generating and executing two similar motor programs at the same time. Motor requirements of one task can interfere with those of another task, leading to a central bottleneck or processing limitation and thus produce dual-task decrements irrespective of cognitive demands. For example, muscular control of respiration (involved in speech production) and posture are interrelated; thus the concurrent performance of a posture and a spoken task requires concurrent response production. Most cognitive tasks used in dual-task studies require 
verbalization such as completing sentences (Shumway-Cook et al., 1997) or repeating a memorized digit sequence (Maylor \& Wing, 1996), indicating that concurrent response production is common in dual-task studies. Yardley, Gardner, Leadbetter, and Lavie (1999) were the first to examine the role of concurrent response production in dual-task performance of a sensorimotor and a cognitive task. Young adults performed a posture task and a task involving verbalization and/or attention both separately and concurrently. Results showed that postural performance deteriorated only when performing a spoken task (irrespective of cognitive demands), presumably due to impaired coordination between respiration and posture (Navon \& Miller, 1987). Likewise, Krampe et al. (under review) observed a pronounced decline in tapping performance when concurrently performing a spoken task rather than an attention demanding 'silent' task. Concurrent response production introduces certain limitations to age-comparative dual-task studies, since empirical evidence suggests age related decrements in generating and executing similar motor programs at the same time. Hartley (2001) asked young and older adults to concurrently perform two cognitive tasks requiring similar (e.g., manual) responses or two tasks requiring different (e.g., manual vs. oral) responses. Older adults showed higher dual-task decrements than young adults but only when performing two tasks requiring similar responses.

Two recent studies (Doumas et al., 2008; Rapp et al., 2006) examined age differences in concurrent posture-cognitive performance while controlling for concurrent response production and group differences in single-task cognitive performance levels. Young and older adults were asked to perform a working memory (WM) task and easy and difficult posture tasks both separately and concurrently. The WM task required verbal responding during (dual-task) posture data collection and the same number of items was verbalized in single-task posture assessments thereby equating concurrent response production across (single-, dual-) task contexts. Task difficulty was individually calibrated in order to equate 
cognitive challenge and single-task cognitive performance levels. Results showed that older but not young adults produced DTCs. These findings suggest that age differences in DTCs emerge even if response production in concurrent tasks do not use the same output modality and without group differences in single-task performance levels. In this respect, these studies already go beyond the Hartley findings (Hartley, 2001; Hartley \& Little, 1999). However it remains possible that the combination of concurrent response production and cognitive load produced the observed dual-task decrements in older adults.

Altogether, the methodological considerations and empirical evidence summarized earlier suggest that verbal responding affects sensorimotor (e.g., tapping or posture) performance and that age differences in dual-task interference could be localized at the level of response generation or age differences in single-task performance levels. Consequently, age differences in dual-task performance could disappear when taking these methodological considerations into account.

\subsection{Outline of the study}

In the present study, we ask whether age differences in concurrent posture-cognitive performance emerge even in the absence of concurrent response production and group differences in single-task cognitive performance levels. To our knowledge, no previous dualtask study has taken these methodological considerations simultaneously into account when assessing concurrent posture and cognitive performance in different age groups. Young and older adults performed a WM task and two posture tasks (standing on a stable and moving platform) both separately and concurrently. The WM task required no verbal responding during posture data collection thereby eliminating concurrent response production. In addition, we individually calibrated WM task difficulty in order to equate cognitive challenge and single-task performance levels across age groups. This way, potential age differences in 
dual-task performance could not be attributed to concurrent response production or underlying single-task differences. Given evidence of sensorimotor and cognitive decline in the course of normal aging, we expected decreased WM capacity and posture performance in older adults. With respect to dual-task performance, we expected to observe pronounced dualtask decrements in older compared to young adults.

\section{Methods}

\subsection{Participants}

Twenty four young $(M=25.42$ years, $S D=3.55$, range $21-34$ years $)$ and 23 older $(M=$ 68 years, $S D=4.46$, range $60-78$ years) adult volunteers participated in the present study. Screening tests included two subtests from the Wechsler Adult Intelligence Scale [WAIS; Wechsler (1981)]: digit span and digit-symbol substitution. Exclusion criteria were the presence of medical conditions or intake of medication known to affect postural control (Tillement et al., 2001). None of the older adults showed impaired mental or general daily function as assessed by the Mini Mental State Examination [MMSE; Folstein, Folstein, \& McHugh (1975)] and the Katz Basic Activities of Daily Living tests [ADL; Katz, Ford, Moskowitz, Jackson, \& Jaffe (1963)] respectively. Prior to testing, participants signed an informed consent form approved by the Psychology Department's ethical committee. Participants were paid 20 euro for their participation. Detailed sample characteristics are given in Table 2.

-Insert Table 2 about here- 


\subsection{Apparatus and tasks}

Posture performance was assessed using the NeuroCom Clinical Research System (NeuroCom International, Inc., Clackamas, OR, USA) consisting of a dynamic 18” dual force plate resting on five force transducers. Forces exerted on the support were recorded on a Pentium $4 \mathrm{PC}$ at a sampling rate of $100 \mathrm{~Hz}$ over the course of the $24 \mathrm{~s}$ trial. Force recordings were used to derive anterior-posterior and medio-lateral position-time functions of the centre of pressure (COP) for each trial. Postural performance was assessed in two platform conditions: stable (involving a fixed support) and moving (involving platform rotations around the pitch axis, frequency: $0.3 \mathrm{~Hz}$, amplitude: $3^{\circ}$ ). Each trial comprised a $4 \mathrm{~s}$ stabilization period, after which presentation of the visual stimuli for the WM task started on a computer screen built into the system's three-sided surround.

The WM task was run on a Pentium D personal computer (Dell Optiplex GX 620, with a Planar monitor). Participants were asked to look at a screen displaying 12 squares organized in a 4 (columns)-by-3 (rows) grid. A number of red apple images appeared, one after the other, with a variable interstimulus interval and each for $400 \mathrm{~ms}$, in a corresponding number of different squares for total trial duration of $20 \mathrm{~s}$. Participants were asked to remember the apples" positions and order of appearance which was pseudo-random assuring that within a given trial the apple did not appear twice in the same square. Performance was expressed as a percentage correct. The number of apples was individually calibrated to equate performance levels at $80 \%$ correct.

The WM task and the two posture tasks were performed both separately (single-task context) and concurrently (dual-task context). In dual-task trials, participants performed the WM task while standing and in single-task assessment while sitting at a table. Single-task assessment of the posture tasks required participants to perform an adapted version of the WM task (which we will further refer to as the control task) while standing. The control task 
was similar to the WM task, included the same number of items, but one (at a random position in the series) or two of the apples (one at a random position and one at the end of the series) were yellow. Participants were asked to remember the position of the final yellow apple. The use of the control task guaranteed comparable visual input and eye- (and possible head-) movements in single- and dual-task contexts, thereby preventing these from artificially creating dual-task effects.

\subsection{Procedure}

Data were collected over the course of two sessions each taking 60 to 90 minutes. In the first session, the difficulty of the WM task was individually calibrated by means of an adaptive testing procedure. Adaptive testing started with 3 (older adults) or 4 (young adults) apples and this number was gradually increased until the target level of $80 \%$ correct performance was reached. In the second session, posture and cognitive performance was assessed in single- and dual-task contexts. Single-task WM performance was assessed at the beginning (four trials), the middle (three trials) and the end (three trials) of the session. Posture performance was assessed in single- (A) and dual-task (B) contexts following an ABBA design where four dual-task trials were preceded and followed by 3 and 2 single-task posture trials respectively. The ABBA design was chosen in order to prevent potential practice or fatigue effects. The stable condition always preceded the moving condition, allowing participants to familiarize themselves with the equipment and preventing potential after effects following the moving platform.

\subsection{Data-analysis}

Postural performance was quantified through fitting an ellipse to the COP trajectory using principal component analysis. The lengths of the ellipse axes were equal to two 
standard deviations of the COP trajectory along each axis, fitting $88 \%$ of the COP trajectory within the ellipse (Duarte \& Zatsiorsky, 2002; Oliveira, Simpson, \& Nadal, 1996), thereby excluding outliers. The ellipse area was calculated using Matlab (Mathworks, Natick, Mass., USA) and represented the outcome measure. Individual trials were given a square-root transformation before averaging within conditions to control for single-trial outliers; means were squared back afterwards. Increases in the size of the area covered by the ellipse reflect an increase in postural instability, indicating decreased posture performance. Statistical analyses were performed using the $88 \%$ confidence ellipse as well as the full COP area; we report only results using the $88 \%$ confidence ellipse are since both measures yielded the same pattern of results.

Statistical analyses were conducted using SAS software, Version 9.1 (2002-2009 SAS Institute Inc., Cary, NC, USA). All reported effects are significant at $p<.05$. Eta square $\left(\eta^{2}\right)$ values are reported as measures of effect size.

\section{Results}

\subsection{Single-task performance}

To test our prediction of age related decline in WM capacity, we considered the number of items remembered at the target performance level. On average, young adults were able to recall $8.17(S D=1.66)$ items with $80 \%$ accuracy while older adults recalled $5.57(S D$ $=.84)$ items, $F(1,45)=45.28, p<.01, \eta^{2}=.50$, consistent with our prediction. Using the number of items determined during the adaptive testing procedure, WM performance was assessed three times over the course of the second session resulting in a total number of 10 trials, the first of which was considered as a warm-up trial and excluded from further analysis. Time of cognitive assessment did not affect performance so the average of nine trials was used to represent single-task WM performance. As intended by individually calibrating task 
difficulty, overall single-task performance was comparable across age groups (young adults: $M=82.23, S D=6.63$; older adults: $M=77.88, S D=8.46$ ), and did not reliably differ from $80 \%$. These results emphasize the effectiveness of our adaptive testing procedure in equating cognitive challenge and single-task performance levels across age groups.

With respect to posture performance, we predicted an age related increase in ellipse areas reflecting decreased posture control. The first (single-task) trial in each platform condition (stable, moving) was considered a warm-up and was excluded from further analysis. The remaining four single- and four dual-task trials for each participant were averaged separately for the two platform conditions. Posture performance is depicted in Figure 1. A mixed design repeated measures analysis of variance (ANOVA) using age group (young vs. old) as between-participants factor and platform condition (stable vs. moving) as withinparticipants factor conducted on ellipse area in single-task contexts showed main effects of platform condition, $F(1,45)=153.30, p<.01, \eta^{2}=.77$ and age, $F(1,45)=11.51, p<.01, \eta^{2}$ $=.20$ and an age-by-platform interaction, $F(1,45)=9.54, p<.01, \eta^{2}=.17$. In single-task contexts, posture performance for standing on a stable platform was similar in the two age groups. On the moving platform, single-task posture performance was better in young as compared with older adults, $F(1,45)=13.86, p<.01, \eta^{2}=.24$, consistent with our prediction.

\subsection{Dual-task effects}

We expected age related decline in dual-task performance. Two mixed design repeated measures ANOVAs were conducted to test the effects of the between-participants factor of age (young vs. older) and the within-participants factors of task context (single vs. dual task) and platform condition (stable vs. moving) on posture and cognitive performance. No reliable effects on cognitive performance were observed, indicating that task context (single vs. dual 
task) did not affect cognitive performance and this was the case for both age groups and platform conditions.

Posture performance is depicted in Figure 1. Greater ellipse areas were observed in dual- compared to single-task contexts, $F(1,45)=7.66, p<.01, \eta^{2}=.15$ and this effect was qualified through an interaction with age, $F(1,45)=4.54, p<.05, \eta^{2}=.09$, platform condition, $F(1,45)=8.36, p<.01, \eta^{2}=.16$, and a three-way interaction involving all three factors, $F(1,45)=5.45, p<.05, \eta^{2}=.11$. This three-way interaction was entirely attributable to the older age group showing decreased posture performance when performing the WM task on the moving platform, as indicated by post-hoc $t$ tests, $t(22)=2.79, p<.05$ (see Figure 1 ).

\section{-Insert Figure 1 about here-}

Dual-task decrements were also expressed as proportional DTCs to account for individual differences in baseline performance. Proportional DTCs were computed for each participant by dividing the absolute difference in single- vs. dual-task performance with single-task performance and multiplying this outcome by 100 [for details on this procedure, see Doumas et al. (2008)]. Positive DTCs indicate declined performance in dual- compared to single-task contexts while negative DTCs indicate improved performance in dual- compared to single-task contexts. DTCs are depicted in Figure 2. A mixed design repeated measures ANOVA was conducted to test the effects of the between-participants factor of age group (young vs. older) and the two within-participants factors of platform condition (stable vs. moving) and modality (posture vs. cognition) on DTCs. There was a main effect of modality on DTCs, indicating that DTCs were higher in posture compared to the cognitive domain, $F$ $(1,45)=6.66, p<.05, \eta^{2}=.13$. No other effects reached significance. DTCs were only 
reliably different from zero in the posture domain for older adults in the moving platform condition, $t(22)=3.18, p<.01$.

-Insert Figure 2 about here-

\section{Discussion}

In the present study, we asked whether age differences in dual-task performance emerge even in the absence of concurrent response production and after control of individual differences in single-task cognitive challenge. In line with our predictions, we found pronounced age differences in posture performance in the more difficult (i.e., moving) platform condition. These effects increased further in dual-task performance. Our findings extend results from previous dual-task studies, and by taking two key aspects of critique related to them into account, they lend further support to the claim that sensorimotor functions like postural control become more cognitively demanding in old age (Doumas et al., 2009; Doumas et al., 2008; Huxhold, Li, Schmiedek, \& Lindenberger, 2006; Maylor \& Wing, 1996; Rapp et al., 2006; Shumway-Cook \& Woollacott, 2000; Shumway-Cook et al. , 1997).

Despite general agreement about increased interference between sensorimotor and cognitive functions in later adulthood, one intriguing aspect varies unsystematically among earlier studies. This aspect relates to older adults' task prioritization, reflecting selective allocation of resources toward sensorimotor functioning at the expense of cognitive performance, when the sensorimotor task becomes very difficult. The typical prioritization pattern in older adults amounts to high DTCs in posture/low DTCs in cognition when the balance task is simple (e.g., stable platform) and the reverse pattern when the posture task is very challenging (e.g., tilting platform, sway-referencing, compromised vision). Task prioritization has been taken as evidence for older adults' efforts to protect their postural 
Interference of posture and cognition

stability thereby adapting to their higher risk of falling and its negative consequences. The unsystematic nature of prioritization becomes evident when one considers recent studies demonstrating this effect (Doumas et al. , 2008; Rapp et al., 2006) and others (Maylor et al., 2001; Maylor \& Wing, 1996) including the present study, showing posture-cognition interference, but not prioritization.

Since the posture tasks used in the present study were identical to the ones used in the study by Rapp et al. (2006), it seems reasonable to assume that WM task differences are responsible for these contradictory findings. The $N$-back task used by Rapp et al. (2006) differs from the WM task in the present study not only with regard to concurrent response production, but also with respect to the pacing of stimulus presentation: in the $N$-back task stimuli are presented with a fixed interstimulus interval while in the WM task used in the present study stimuli are presented with a variable interstimulus interval, presumably allowing for self-paced processing and more flexible resource allocation. The absence of cognitive DTCs suggests that, overall, the WM task used in the present study is less challenging than the cognitive tasks used in previous studies [proportional DTCs in cognition in the most difficult sensorimotor condition: 39\% in Lindenberger et al. (2000); 25\% in Li, Lindenberger, Freund, \& Baltes (2001); 12\% in Doumas et al. (2008); 11\% in Rapp et al. (2006)]. Perhaps older adults felt safe and secure enough to allow a drop in posture performance in the most difficult posture condition in order to maintain cognitive performance at target level. Further research is needed to specify the role of posture and cognitive task difficulty in dual-task performance and age differences therein. 
References

Brown, L. A., Shumway-Cook, A., \& Woollacott, M. H. (1999). Attentional demands and postural recovery: The effects of aging. Journal of Gerontology: Medical Sciences, 54A, M165-M171.

Doumas, M., Rapp, M. A., \& Krampe, R. T. (2009). Working memory and postural control: adult age differences in potential for improvement, task priority, and dual tasking. Journal of Gerontology: Psychological Sciences, 10.1093/geronb/gbp009.

Doumas, M., Smolders, C., \& Krampe, R. T. (2008). Task prioritization in aging: effects of sensory information on concurrent posture and memory performance. Experimental Brain Research, 187(2), 275-281.

Duarte, M., \& Zatsiorsky, V. M. (2002). Effects of body lean and visual information on the equilibrium maintenance during stance. Experimental Brain Research, 146(1), 60-69.

Folstein, M., Folstein, S.E., McHugh, P.R. (1975). "Mini-Mental State" a Practical Method for Grading the Cognitive Status of Patients for the Clinicial. Journal of Psychiatric Research, 12(3), 189-198.

Hartley, A. A. (2001). Age differences in dual-task interference are localized to responsegeneration processes. Psychology and Aging, 16(1), 47-54.

Hartley, A. A., \& Little, D. M. (1999). Age-related differences and similarities in dual-task interference. Journal of Experimental Psychology: General, 128, 416-449.

Heuninckx, S., Debaere, F., Wenderoth, N., Verschueren, S., \& Swinnen, S. P. (2004). Ipsilateral coordination deficits and central processing requirements associated with coordination as a function of aging. Journal of Gerontolology: Psychological Sciences, 59(5), P225-232. 
Interference of posture and cognition

Huxhold, O., Li, S., Schmiedek, F., \& Lindenberger, U. (2006). Dual-tasking postural control: aging and the effects of cognitive demand in conjunction with focus of attention. Brain Research Bulletin, 69(3), 294-305.

Katz, S., Ford, A.B., Moskowitz, R.W., Jackson, B.A., \& Jaffe, M.W. . (1963). Studies of illness in the aged. The index of ADL: A standardized measure of biological and psychosocial function. Journal of the American Medical Association, 185, 914-919.

Kemper, S., Herman, R. E., \& Lian, C. H. T. (2003). The costs of doing two things at once for young and older adults: Talking while walking, finger tapping, and ignoring speech or noise. Psychology and Aging, 18, 181-192.

Krampe, R., Doumas, M., Lavryssen, A., \& Rapp, M. (under review). Attention, working memory, and executive control in repetitive movement timing: effects of age and concurrent task demands.

Lacour, M., Bernard-Demanze, L., \& Dumitrescu, M. (2008). Posture control, aging, and attention resources: models and posture-analysis methods. Neurophysiol Clin, 38(6), 411-421.

Lajoie, Y., Teasdale, N., Bard, C., \& Fleury, M. (1996). Upright standing and gait: Are there changes in attentional requirements related to normal aging? Experimental Aging Research, 22, 185-198.

Li, K. Z., Krampe, R. T., \& Bondar, A. (2005). An ecological approach to studying aging and dual-task performance. In R. W. Engle, G. Sedek, U. von Hecker \& D. N. McIntosh (Eds.), Cognitive limitations in aging and psychopathology (pp. 190-218). New York: Cambridge University Press.

Li, K. Z., Lindenberger, U., Freund, A. M., \& Baltes, P. B. (2001). Walking while memorizing: A SOC study of age-related differences in compensatory behavior under dual-task conditions. Psychological Science, 12, 230-237. 
Lindenberger, U., Marsiske, M., \& Baltes, P. B. (2000). Memorizing while walking: Increase in dual-task costs from young adulthood to old age. Psychology and Aging, 15, 417436.

Lovden, M., Schaefer, S., Pohlmeyer, A. E., \& Lindenberger, U. (2008). Walking variability and working-memory load in aging: a dual-process account relating cognitive control to motor control performance. Journal of Gerontology: Psychological Sciences, 63(3), P121-128.

Maylor, E. A., Allison, S., \& Wing, A. M. (2001). Effects of spatial and nonspatial cognitive activity on postural stability. British Journal of Psychology, 92, 319-338.

Maylor, E. A., \& Wing, A. M. (1996). Age differences in postural stability are increased by additional cognitive demands. Journal of Gerontology: Psychological Sciences, 51B, 143-154.

Navon, D., \& Miller, J. O. (1987). The role of outcome conflict in dual-task interference. Journal of Experimental Psychology: Human Perception and Performance, 13(438448).

Oliveira, L. F., Simpson, D. M., \& Nadal, J. (1996). Calculation of area of stabilometric signals using principal component analysis. Physiological Measures, 17(4), 305-312.

Rapp, M., Krampe, R. T., \& Baltes, P. B. (2006). Adaptive task prioritization in aging:

Selective resource allocation to postural control is preserved in Alzheimer disease. American Journal of Geriatric Psychiatry 14(1), 52-61.

Shumway-Cook, A., \& Woollacott, M. (2000). Attentional demands and postural control: The effect of sensory context. Journal of Gerontology: Medical Sciences, 55A, M10-M16.

Shumway-Cook, A., Woollacott, M., Kerns, K. A., \& Baldwin, M. (1997). The effects of two types of cognitive tasks on postural stability in older adults with and without a history of falls. Journal of Gerontology: Medical Sciences, 52A, M232-M240. 
Interference of posture and cognition

Somberg, B. L., \& Salthouse, T. A. (1982). Divided attention abilities in young and old adults. Journal of Experimental Psychology: Human Perception and Performance, 8, 651-663.

Tillement, J. P., Albengres, E., Cottin, D., Klouz, A., Arkoub, H., \& Le Louet, H. (2001). [The risk of falling due to benzodiazepine administration, alone or in combination, in elderly subjects]. Therapie, 56(4), 435-440.

Voelcker-Rehage, C., \& Alberts, J. L. (2007). Effect of motor practice on dual-task performance in older adults. Journal of Gerontology: Psychological Sciences, 62(3), P141-148.

Voelcker-Rehage, C., Stronge, A. J., \& Alberts, J. L. (2006). Age-related differences in working memory and force control under dual-task conditions. Aging, Neuropsychology, and Cognition, 13(3-4), 366-384.

Yardley, L., Gardner, M., Leadbetter, A., \& Lavie, N. (1999). Effect of articulatory and mental tasks on postural control. Neuroreport, 10(2), 215-219. 
Table 1A.

Overview of studies assessing sensorimotor and cognitive performance in different adult age groups, using the same task difficulty for all age groups

\begin{tabular}{|c|c|c|c|c|}
\hline Ref. & Cognitive task & Sensorimotor task & Dual-task costs in cognitive task & Dual-task costs in sensorimotor task \\
\hline $\begin{array}{l}\text { Maylor \& Wing } \\
(1996)^{2: 57 ; 3: 77}\end{array}$ & $\begin{array}{l}\text { Random digit generation }{ }^{1}, \\
\text { Brooks' spatial memory }{ }^{1}, \\
\text { backward digit recall }^{1}, \text { silent } \\
\text { counting }^{0} \text {, counting backward } \\
\text { in threes }\end{array}$ & Posture (stable support) & None & $\begin{array}{l}\text { Increased age differences when performing } \\
\text { visuo-spatial tasks }\end{array}$ \\
\hline $\begin{array}{l}\text { Lajoie et al. } \\
(1996)^{1: 26 ; 3: 71}\end{array}$ & Auditory $\mathrm{RT}^{1}$ & $\begin{array}{l}\text { Posture (broad support, } \\
\text { narrow support) and walking }\end{array}$ & $\begin{array}{l}\text { YA and OA in posture en } \\
\text { walking, pronounced for OA in } \\
\text { difficult posture condition }\end{array}$ & OA in walking \\
\hline $\begin{array}{l}\text { Shumway-Cook } \\
\text { et al. }(1997)^{1: 31} \\
\text { 3: } 74\end{array}$ & $\begin{array}{l}\text { Sentence completion }{ }^{1} \text {, visual } \\
\text { perception matching }^{1}\end{array}$ & $\begin{array}{l}\text { Posture (stable vs. compliant } \\
\text { support) }\end{array}$ & None & $\mathrm{OA}$ in difficult posture condition \\
\hline $\begin{array}{l}\text { Brown et al. } \\
(1999)^{1: 25 ; 3: 79}\end{array}$ & Counting backwards ${ }^{1}$ & Posture (perturbations) & YA and $\mathrm{OA}$, pronounced in $\mathrm{OA}$ & $\mathrm{YA}$ and $\mathrm{OA}$, pronounced in $\mathrm{OA}$ \\
\hline $\begin{array}{l}\text { Lindenberger et } \\
\text { al. }(2000)^{1: 24 ; 2:} \\
45 ; 3: 65\end{array}$ & Memorizing word lists ${ }^{0}$ & $\begin{array}{l}\text { Walking (oval vs. aperiodic } \\
\text { walking track) }\end{array}$ & $\begin{array}{l}\text { YA in difficult walking condition; } \\
\text { OA in both walking conditions }\end{array}$ & $\mathrm{YA}$ and $\mathrm{OA}$, pronounced in $\mathrm{OA}$ \\
\hline $\begin{array}{l}\text { Shumway-Cook } \\
\& \text { Woollacott } \\
(2000)^{1: 35 ; 3: 75}\end{array}$ & Auditory choice $\mathrm{RT}^{1}$ & $\begin{array}{l}\text { Posture, six sensory } \\
\text { conditions }\end{array}$ & $\begin{array}{l}\text { OA in three most difficult posture } \\
\text { conditions }\end{array}$ & OA in two most difficult posture conditions \\
\hline $\begin{array}{l}\text { Maylor et al. } \\
(2001)^{1: 22,36,44} \\
2: 54 ; 3: 65,74\end{array}$ & $\begin{array}{l}\text { Brooks' spatial and non- } \\
\text { spatial task }^{0}\end{array}$ & Posture & Non & $\begin{array}{l}\text { Increased age differences when performing } \\
\text { spatial WM task }\end{array}$ \\
\hline $\begin{array}{l}\text { Kemper et al. } \\
(2003)^{1: 22 ; 3: 73}\end{array}$ & $\begin{array}{l}\text { Speech production }{ }^{1} \text { (fluency, } \\
\text { complexity, content) }\end{array}$ & $\begin{array}{l}\text { Walking, finger tapping, } \\
\text { ignoring speech or noise }\end{array}$ & $\begin{array}{l}\text { YA show DTCs in complexity, } \\
\text { OA show DTCs in fluency }\end{array}$ & $\begin{array}{l}\text {-DTCs in tapping, DTC in walking, not } \\
\text { age-differential }\end{array}$ \\
\hline $\begin{array}{l}\text { Heuninckx et } \\
\text { al. }(2004)^{1: 25 ; 3:}\end{array}$ & Line figure judgement task ${ }^{0}$ & $\begin{array}{l}\text { Concurrent hand-foot } \\
\text { movements }\end{array}$ & None & $\begin{array}{l}\text { Decreased accuracy and stability in OA, } \\
\text { decreased stability in YA, age differences } \\
\text { disappear after equating sensorimotor single- } \\
\text { task performance level }\end{array}$ \\
\hline $\begin{array}{l}\text { Huxhold et al. } \\
(2006)^{1: 25 ; 3: 70}\end{array}$ & $\begin{array}{l}\text { Choice RT }{ }^{2}, \text { 2-back }{ }^{2} \text {, spatial } \\
\text { 2-back }\end{array}$ & Posture (stable support) & None & $\begin{array}{l}\text { OA when performing difficult cognitive } \\
\text { task. YA and OA show -DTCs when } \\
\text { performing easy cognitive task }\end{array}$ \\
\hline $\begin{array}{l}\text { Voelcker- } \\
\text { Rehage et al. }\end{array}$ & $N$-back task ${ }^{1}$ & Force-tracking & $\mathrm{OA}$ & OA \\
\hline
\end{tabular}

Rehage et al.

$(2006)^{1: 25 ; 3: 74}$ 

Lovden et al.
$N$-back task
Walking
None
-DTCs for YA and OA when performing (2008) $)^{1: 25 ; 3: 74}$ easy cognitive task, -DTCs for YA when performing difficult cognitive task

Note. Abbreviations (in alphabetical order): OA (older adults), Ref. (reference), RT (reaction time), YA (young adults). Digits behind author(s) refer to age groups included in the study $(1=$ young, $2=$ middle-aged, $3=$ older), digits in italic refer to the mean ages of these groups. Digits behind cognitive tasks refer to response mode during sensorimotor data collection $\left(0=\right.$ no overt responding, $1=$ verbal responding, $1^{*}=$ verbal responding but controlled for, $2=$ button pressing). 
Table 1B.

\begin{tabular}{|c|c|c|c|c|}
\hline Ref. & Cognitive task & Sensorimotor task & Dual-task costs in cognitive task & Dual-task costs in sensorimotor task \\
\hline $\begin{array}{l}\text { Li et al. (2001) } \\
\text { 1: } 25 ; 3: 66\end{array}$ & Episodic $\mathrm{WM}^{0}$ & $\begin{array}{l}\text { Walking (with or without } \\
\text { obstacles) }\end{array}$ & $\begin{array}{l}\text { OA in both walking conditions, } \\
\text { pronounced in difficult walking } \\
\text { condition }\end{array}$ & $\begin{array}{l}\text { YO \& OA, pronounced in OA and difficult } \\
\text { walking condition }\end{array}$ \\
\hline $\begin{array}{l}\text { Rapp et al. } \\
(2006)^{1: 24 ; 3: 69}\end{array}$ & $N$-back task ${ }^{1 *}$ & $\begin{array}{l}\text { Posture (stable vs. moving } \\
\text { platform) }\end{array}$ & OA in easy posture condition & OA in difficult posture condition \\
\hline $\begin{array}{l}\text { Doumas et al. } \\
(2008)^{1: 22 ; 3: 71}\end{array}$ & $N$-back task ${ }^{1 *}$ & $\begin{array}{l}\text { Posture, three sensory } \\
\text { conditions }\end{array}$ & OA in easy posture condition & $\mathrm{s}$ in difficult $\mathrm{P}$ condition \\
\hline $\begin{array}{l}\text { Doumas et al. } \\
(2009)^{1: 27 ; 3: 67}\end{array}$ & $N$-back task ${ }^{1 *}$ & Posture, moving platform & None & None \\
\hline $\begin{array}{l}\text { Krampe et al. } \\
\text { (under } \\
\text { review) }\end{array}$ & $\begin{array}{l}\text { Digit monitoring } \\
\text { back }^{0}, 0 \text {-back }\end{array}$ & $\begin{array}{l}\text { Tapping (slow and fast } \\
\text { tempos) }\end{array}$ & $\begin{array}{l}\text { In slow but not fast tapping, } \\
\text { especially in older adults }\end{array}$ & OA, especially in slow tapping \\
\hline
\end{tabular}

Note. Abbreviations (in alphabetical order): OA (older adults), Ref. (reference), RT (reaction time), YA (young adults). Digits behind author(s) refer to age groups included in the study ( $1=$ young, $2=$ middle-aged, $3=$ older), digits in italic refer to the mean ages of these groups. Digits behind cognitive tasks refer to response mode during sensorimotor data collection $\left(0=\right.$ no overt responding, $1=$ verbal responding, $1^{*}=$ verbal responding but controlled for, $2=$ button pressing $)$. 
Table 2. Sample characteristics, group means (standard deviations in parentheses); * denotes significant age difference at .05-level

\begin{tabular}{|l|l|l|}
\hline & Young adults & Older adults \\
\hline Age (yrs) & $25.42(3.55)$ & $68(4.46)$ \\
\hline Body mass index $\left(\mathrm{kg} / \mathrm{m}^{2}\right)$ & $23.69(4)$ & $25.48(3.07)$ \\
\hline $\begin{array}{l}\text { Self-evaluation of current health } \\
\text { status in comparison with people of } \\
\text { same age (score 1-5 where 5= 'a lot } \\
\text { better', 4= 'better', 3= 'the same as', } \\
\text { 2= 'worse', 1= 'a lot worse') }\end{array}$ & $4.17(.56)$ & $4.35(.64)$ \\
\hline $\begin{array}{l}\text { Years of formal education } \\
\text { DS-forward, raw score }\end{array}$ & $17.54(3.06)$ & $14.39(3.24) *$ \\
\hline DS-backward, raw score & $7.58(1.79)$ & $6.65(1.43)$ \\
\hline
\end{tabular}


List of figures

Figure 1. Posture performance expressed as the area of the fitted ellipse in the two platform conditions (stable, moving) for young $(n=24)$ and older $(n=23)$ adults. In single-task contexts participants were standing on the platform while performing the control task; in dualtask contexts participants were standing on the platform while performing the WM task. Error bars represent $+/-1.96$ standard errors of the mean.

Figure 2. Proportional DTCs for cognition and posture in the two platform conditions (stable, moving) for young $(n=24)$ and older $(n=23)$ adults. Error bars represent $+/-1.96$ standard errors of the mean. 


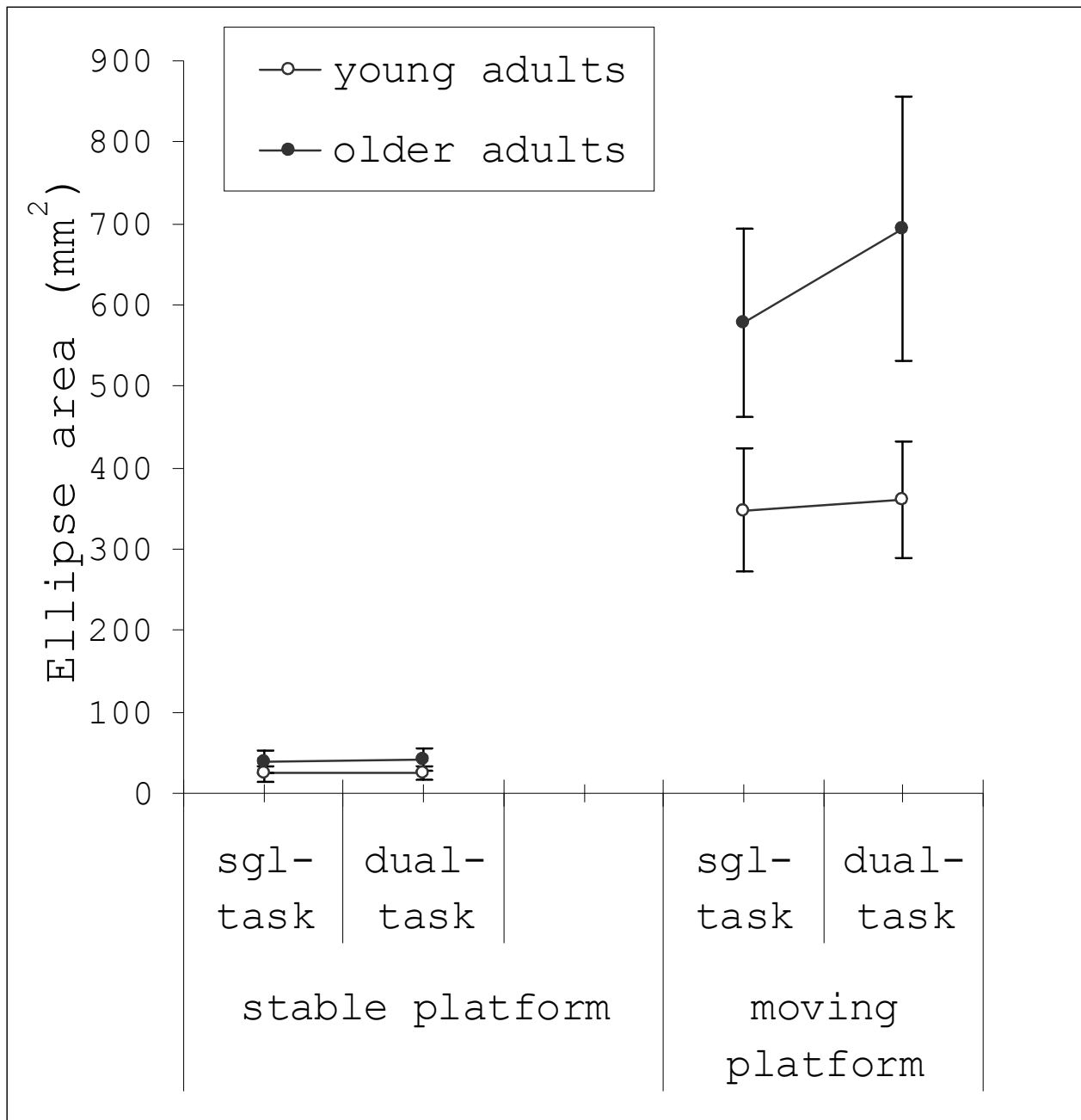




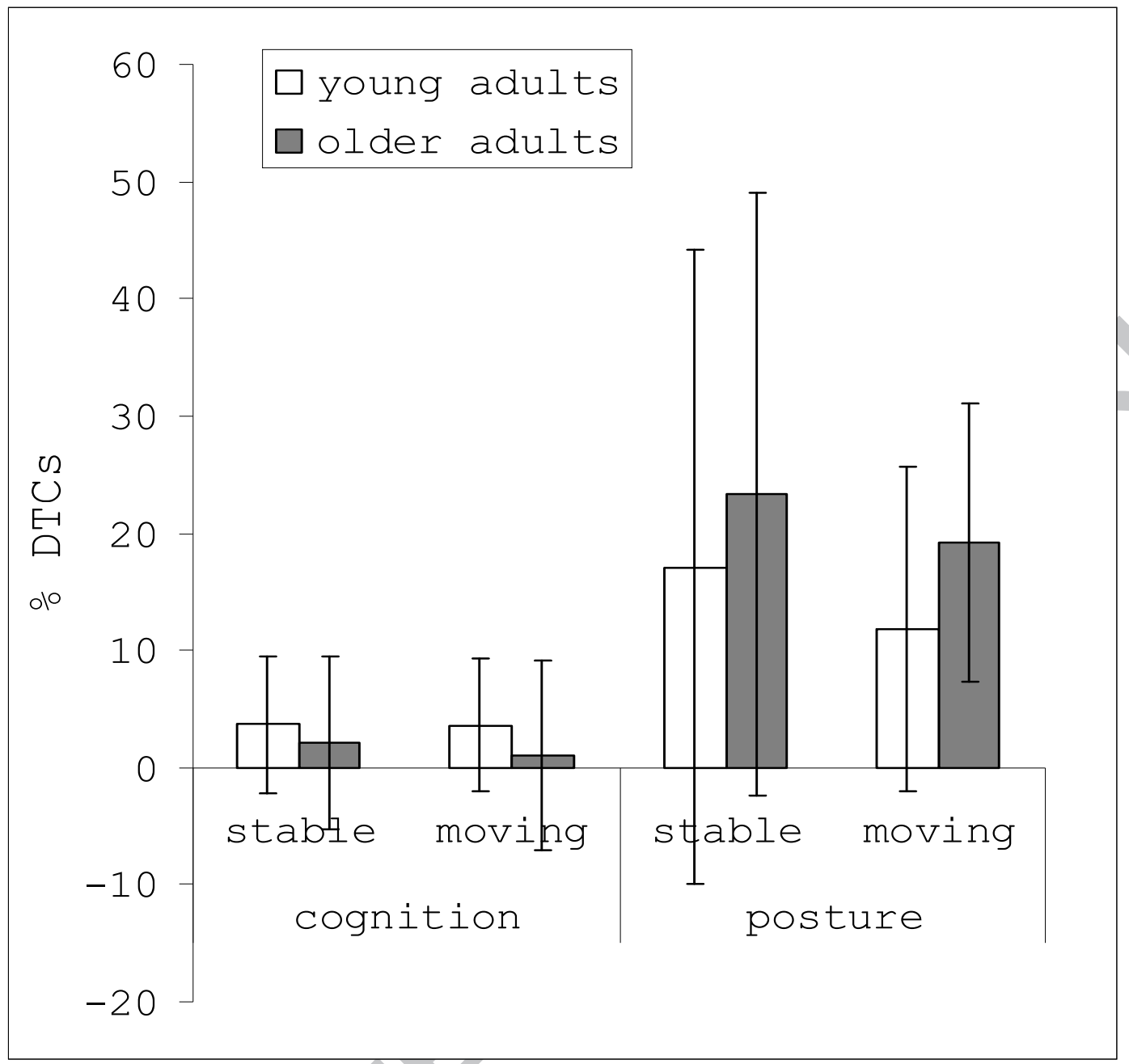




\begin{abstract}
We investigated adult age differences in dual-task costs in cognitive-sensorimotor settings without concurrent response production and with individually adjusted resource demands for the cognitive task. Twenty-four young adults $(M=25.42$ years, $S D=3.55)$ and 23 older adults $(M=68$ years, $S D=4.46)$ performed a cognitive task and two postural control tasks (standing on a stable and moving platform) both separately (single-task context) and concurrently (dual-task context). The cognitive task did not require response production during posture data collection and its difficulty was individually adjusted to $80 \%$ correct performance under single-task conditions. Results showed pronounced age differences in postural control in the moving platform condition, which increased further under dual-task conditions. Our findings support the assumption of increased cognitive resource demands for postural control in older adults. They extend existing work by taking two shortcomings of previous studies into account. We discuss cognitive and posture task constraints in this and previous studies as factors determining multi-tasking and its changes in later adulthood.
\end{abstract}

Abstract: 165 words

Keywords: dual task, age differences, posture, cognition

PsycINFO Classification code 23302340 